\title{
Conditioning Effects of Chronic Infusions of Dobutamine
}

\author{
COMPARISON WITH EXERCISE TRAINING
}

\author{
Chang-seng Liang, Ronald R. Tuttle, William B. Hood, Jr., and Haralambos \\ Gavras, Departments of Medicine and Pharmacology, and the Cardiovascular \\ Institute, Boston University School of Medicine, Thorndike Memorial \\ Laboratory, Boston City Hospital, Boston, Massachusetts 02118; The Lilly \\ Research Laboratories, Indianapolis, Indiana 46206
}

A B S TRACT We studied the conditioning effects of chronic infusion of dobutamine and exercise training in three groups of chronically instrumented dogs. One group was infused with normal saline, a second group was infused with dobutamine ( $40 \mu \mathrm{g} / \mathrm{kg}$ per min), and the third group was exercised on a treadmill at $4 \mathrm{mph}$, up a $10^{\circ}$ incline. Each group was either infused or exercised for $2 \mathrm{~h}$ a day, $5 \mathrm{~d}$ a week for 5 consecutive wk. Resting heart rate and arterial blood lactate concentration, measured at weekly intervals, decreased progressively in the dobutamine and exercise groups, but not in the group that received normal saline infusion. Cardiovascular responses to submaximal treadmill exercise were not changed by 5 wk of normal saline infusion. However, the increases in heart rate, cardiac output, mean aortic blood pressure, arterial blood lactate, plasma renin activity, and norepinephrine concentration during exercise were significantly smaller after $5 \mathrm{wk}$ of conditioning with either dobutamine or exercise training. After conditioning, the increases in arteriovenous oxygen difference during exercise were larger in the latter two groups, but the increases in total body oxygen consumption did not differ before and after conditioning.

To assess ventricular function, we intravenously infused methoxamine both before and after conditioning. The slope of the line that related systolic aortic blood pressure and mean left atrial pressure increased in the animals conditioned with either dobutamine or exercise, indicating enhanced myocardial contractility. Left ventricular blood flow was lower in these two groups of animals than it was in the normal saline group. Left ventricular weight did not differ among the three groups.

Our results show that chronic infusion of dobutamine produced cardiovascular and metabolic conditioning effects like those produced by exercise training, and further suggest that sympathetic stimulation during exercise plays a role in physical conditioning.

\section{INTRODUCTION}

Prolonged physical exercise produces a variety of biochemical and cardiovascular changes in man. These adaptive changes, known as physical conditioning, include a decrease in resting heart rate $(1,2)$, and increases in skeletal muscle mitochondrial enzymes (3), maximum exercise oxygen consumption (1-3), and myocardial contractility $(1,4)$. The increase in maximum oxygen consumption probably is accounted for by the enhanced capacity of skeletal muscle to extract oxygen as well as by the increase in oxygen delivery. Lower levels of blood and skeletal muscle lactate are also observed in trained subjects, both at rest and during exercise (3). As a result, a trained individual is able to respond to the same work load with less effort and to achieve a higher maximum work load than a sedentary person.

The hemodynamic and metabolic changes that occur during muscular exercise are well-known (5), and many of them are caused by sympathetic stimulation (5-7). It is, however, not known what role sympathetic stimulation plays in the development of the physical conditioning response. A preliminary report (8) showed that repetitive stimulation with the sympathomimetic drug, dobutamine, caused a conditioning response in dogs with coronary arterial narrowing such that there was a decrease in resting heart rate and an apparent increase in myocardial contractility. Dobutamine is a new synthetic catecholamine which, when infused intravenously, elicits increases in heart rate, myocardial contractility, arterial blood pressure, and coronary and skeletal muscle blood flows that resemble the effects of exercise. Unlike the naturally occurring 
catecholamines (dopamine, norepinephrine, and epinephrine), dobutamine has little $\alpha$-adrenergic action, consequently dobutamine cannot readily induce rises in blood pressure greater than those induced by exercise. Yet, unlike isoproterenol, dobutamine does not have so much $\beta$-adrenergic vasodilatory activity that it lowers arterial blood pressure. Also, dobutamine is less likely to cause arrhythmias or myocardial necrosis than are the naturally occurring catecholamines or isoproterenol $(9,10$, data on file at the Lilly Research Laboratories).

The purpose of this study was to compare the conditioning effects of chronic dobutamine infusion and exercise in normal dogs. Our results show that chronic dobutamine infusion produced cardiovascular and metabolic changes like physical conditioning, and suggest that sympathetic stimulation may play a major role in conditioning.

\section{METHODS}

Pure-bred adult beagles that weighed between 8.6 and $15.0 \mathrm{~kg}$ were used. They were screened for their ability to run on a treadmill at $4 \mathrm{mph}$ up a $10^{\circ}$ incline; only those dogs that were free of heart worm infestation and that would run without coercion for more than 20 min were chosen for the study. The animals were housed in individual cages for $1 \mathrm{wk}$ before they were anesthetized with pentobarbital sodium $(25 \mathrm{mg} / \mathrm{kg}$, i.v.). A Harvard respirator (Harvard Apparatus Company, Inc., Millis, Mass.) was used to maintain pulmonary ventilation. A sterile left thoracotomy was done via the fifth intercostal space. Heparin-filled Tygon catheters (i.d., $1.02 \mathrm{~mm}$; Norton Co., Plastics \& Synthetics Div., Akron, Ohio) were inserted into the main pulmonary artery, left atrium, and the descending thoracic aorta. The catheters were then exteriorized through the interscapular space and secured at the back of the dog's neck. After the thoracotomy was closed, the animal was returned to its cage, and was allowed to recover for 2 wks. Veterinary procaine penicillin G (Pfizer Chemical Div., New York), 600,000 U/d, was given intramuscularly for $6 \mathrm{~d}$ postoperatively, and ferrous sulfate (325 $\mathrm{mg} / \mathrm{d}$ ) was administered orally throughout the study period. The catheters were checked for patency and refilled with heparin $3 \mathrm{~d}$ a week.

2 wk after the surgery, the animals were allowed to stand on a standard 1-10 mph mobil treadmill (Warren E. Collins, Inc., Braintree, Mass.). The chronically indwelling catheters were connected to Statham P23Db pressure transducers (Statham Instruments, Inc., Oxnard, Calif.) and an 8-channel Brush 480 Recorder (Gould Inc., Instruments Div., Cleveland, Ohio) to measure blood pressures and heart rate. Cardiac output was determined by indocyanine green (Cardio-Green, Hynson, Westcott \& Dunning, Inc., Baltimore, Md.) injected into the pulmonary artery, with a Gilford model 140 cardiac output system (Gilford Instrument Laboratories Inc., Oberlin, Ohio). These hemodynamic measurements were taken in triplicate $5 \mathrm{~min}$ apart during a resting state when the animal stood quietly on the treadmill, and again $5,10,15$, and 20 min after the animal began running at $4 \mathrm{mph}$ up a $10^{\circ}$ incline. Averages were made in each dog of the three measurements of each hemodynamic variable during the control period. Measurements taken at 10, 15, and 20 min of exercise, during which a steady state was achieved, were also averaged. These averages for the two experimental periods are reported as resting and exercise values in Results. In addition, aortic and pulmonary artery blood samples were taken during the resting period and after $15 \mathrm{~min}$ of treadmill exercise to measure oxygen content by gas chromatography (11). Simultaneously, aortic blood samples were obtained to measure $\mathrm{pH}, \mathrm{PO}_{2}$, and $\mathrm{PCO}_{2}$ on a Radiometer $\mathrm{PHM} 71$ acid base analyzer (Rainin Instrument Co. Inc., Woburn, Mass.), and to measure lactate (12), pyruvate (13), plasma renin activity (14), and norepinephrine (15). Total body oxygen consumption was calculated from the equation of cardiac output times the difference between aortic and pulmonary arterial blood oxygen contents (arteriovenous oxygen difference).

$1 \mathrm{~h}$ after the treadmill exercise, we placed the animal in a prone position and continuously monitored aortic and left atrial blood pressures as ventricular afterload was elevated with methoxamine hydrochloride (Vasoxyl, Burroughs Wellcome Co., Research Triangle Park, North Carolina). The peak systolic aortic blood pressures were then plotted against left atrial pressures to construct a left ventricular function curve. Methoxamine is a pure $\alpha$-adrenergic agonist, which produces peripheral vasoconstriction and has no direct effect on the heart (16). It was diluted in normal saline to a concentration of $0.33 \mathrm{mg} / \mathrm{ml}$, and infused into a peripheral vein at successively increasing rates of $0.19,0.38$, and $0.78 \mathrm{ml} / \mathrm{min}$, with a Harvard infusion pump. The infusion was stopped when the systolic aortic pressure reached $225 \mathrm{~mm} \mathrm{Hg}$ or when the aortic blood pressure achieved a plateau at the highest dose of methoxamine. At the end of methoxamine infusion, $5 \mathrm{mg}$ of phentolamine mesylate (Regitine, CIBA-Geigy Corp., Pharmaceuticals Div., Summit, N. J.) was administered to reverse the effects of methoxamine and the dog was returned to the cage.

The dogs were divided into three groups the day after the initial treadmill exercise test and methoxamine infusion. Two of the groups remained sedentary and were infused with normal saline or dobutamine $(40 \mu \mathrm{g} / \mathrm{kg}$ per min; Dobutrex, Eli Lilly \& Co., Indianapolis, Indiana) at a rate of 0.38 $\mathrm{ml} / \mathrm{min}$ with a Harvard infusion pump for $2 \mathrm{~h}$ a day, $5 \mathrm{~d}$ a week for 5 consecutive wk. The third group was exercised on the treadmill at $4 \mathrm{mph}$ up a $10^{\circ}$ incline for the same intervals of time as the two other groups that received infusions. Resting heart rate, aortic blood pressure, and arterial lactate concentration were determined at weekly intervals.

$24 \mathrm{~h}$ after the end of the 5-wk infusion or exercise period, the animal was restudied with treadmill exercise and methoxamine infusion. In addition to the hemodynamic and metabolic parameters mentioned above, left ventricular blood flow was measured at rest before treadmill exercise by a modification (17) of the radioactive microsphere method of Rudolph and Heymann (18). 450,000 microspheres, $15 \pm 3 \mu \mathrm{m}$ in diameter, and labeled with cerium 141 at a specific activity of $10 \mathrm{mCi} / \mathrm{g}$, were injected into the left atrium via the atrial catheter. This was immediately flushed with $10 \mathrm{ml}$ of normal saline over a 30-s period. Arterial reference blood was withdrawn with a Harvard pump at a rate of $7.75 \mathrm{ml} / \mathrm{min}$, beginning $10 \mathrm{~s}$ before the injection of microspheres and continuing for $80 \mathrm{~s}$ thereafter. At the end of the experiment, the animal was sacrificed with pentobarbital sodium and the heart excised. The left ventricle including its septum was dissected out, rinsed, weighed, and then ashed. The content of radioactivity was measured with a Packard gamma spectrometer and a model 9012 multichannel analyzer (Packard Instrument Co., Inc., Downers Grove, Ill.). Left ventricular blood flow was calculated by the reference sample method (17).

The data were treated with parametric statistics; values reported in Results are means $\pm S E$. Analysis of variance was used to determine the significance of differences among the three groups of experimental animals, whereas Student's 
$t$ test for paired comparisons was used to determine the statistical significance of a difference between two means in the same group. The weekly measurements of resting heart rate, aortic blood pressure, and arterial lactate concentration in the three groups, however, were treated with twoway analysis of variance for independent groups with trend analysis (19), and the significance of the differences between control and experimental values was determined by Dunnett's test (20). The difference was considered significant if $P<0.05$. Linear regression analysis was used to determine the relationship between systolic aortic and left atrial blood pressures obtained during methoxamine infusion.

\section{RESULTS}

18 dogs completed the 5-wk course of treadmill exercise or infusion of normal saline or dobutamine. There were six dogs in each group. All animals appeared healthy during the course of experiments; body weights did not change significantly in any of the groups (Table I). Resting heart rate and arterial lactate concentration decreased gradually during the 5-week period in the groups of animals with dobutamine infusion and treadmill exercise (Fig. 1). These changes, however, were absent in dogs that were infused with normal saline for the same period of time. In addition, resting mean aortic blood pressure did not change significantly over the 5-wk period in any of the three groups (normal saline group, from $98 \pm 2$ to $98 \pm 5 \mathrm{~mm} \mathrm{Hg}$; dobutamine group, from $96 \pm 4$ to $96 \pm 3 \mathrm{~mm} \mathrm{Hg}$; exercise group, from $101 \pm 2$ to $105 \pm 3 \mathrm{~mm} \mathrm{Hg}$ ).

Responses to submaximal treadmill exercise. Total body oxygen consumption increased during the initial treadmill exercise at week 0 as follows: in the control group that was subsequently infused with normal saline it rose from $127 \pm 10$ to $405 \pm 42 \mathrm{ml} / \mathrm{min}$, in the group subsequently infused with dobutamine it increased from $121 \pm 3$ to $445 \pm 42 \mathrm{ml} / \mathrm{min}$, and in the

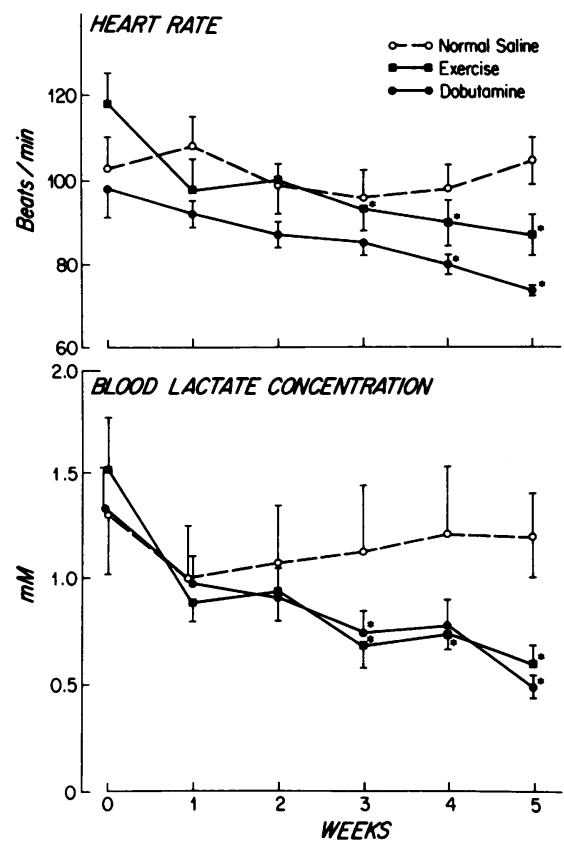

FIGURE 1 Changes in resting heart rate and arterial blood lactate concentration over a 5-wk period in three groups of conscious dogs. Two of the groups received infusions of normal saline and dobutamine (40 $\mu \mathrm{g} / \mathrm{kg}$ per min) $2 \mathrm{~h}$ a day, $5 \mathrm{~d}$ a week for 5 consecutive wk. The third group was exercised on a treadmill at $4 \mathrm{mph}, 10^{\circ}$ inclination, for the same period of time as the first two groups. $n=6$ in each group. Bars show SE. *, Values that are statistically different from the corresponding control value at week 0 at $P<0.05$, as determined by two-way analysis of variance with trend analysis (19) and Dunnett's test (20).

group subsequently conditioned with exercise it increased from $133 \pm 9$ to $408 \pm 39 \mathrm{ml} / \mathrm{min}$. Exerciseinduced increases in cardiac output, aortic blood pres-

TABLE I

Hemodynamic Measurements

\begin{tabular}{|c|c|c|c|c|c|c|c|c|c|c|}
\hline \multirow[b]{2}{*}{ Group } & \multirow[b]{2}{*}{ wk } & \multirow[b]{2}{*}{ Body wt } & \multicolumn{2}{|c|}{ Cardiac output } & \multicolumn{2}{|c|}{ Heart rate } & \multicolumn{2}{|c|}{ Aortic blood pressure } & \multicolumn{2}{|c|}{ Stroke volume } \\
\hline & & & Resting & Exercise & Resting & Exercise & Resting & Exercise & Resting & Exercise \\
\hline & & $\mathrm{kg}$ & \multicolumn{2}{|c|}{ liters/min } & \multicolumn{2}{|c|}{ beats/min } & \multicolumn{2}{|c|}{$m m \mathrm{Hg}$} & \multicolumn{2}{|c|}{$m l$} \\
\hline \multirow[t]{2}{*}{ Normal saline } & 0 & $11.0 \pm 1.2$ & $2.82 \pm 0.21$ & $5.56 \pm 0.37^{*}$ & $113 \pm 7$ & $187 \pm 6^{*}$ & $109 \pm 2$ & $128 \pm 3^{*}$ & $27 \pm 3$ & $30 \pm 2$ \\
\hline & 5 & $10.8 \pm 1.5$ & $3.07 \pm 0.37$ & $5.97 \pm 0.26^{*}$ & $120 \pm 9$ & $186 \pm 5^{*}$ & $102 \pm 4$ & $126 \pm 6^{*}$ & $26 \pm 4$ & $32 \pm 1$ \\
\hline \multirow[t]{2}{*}{ Dobutamine } & 0 & $12.7 \pm 0.4$ & $2.95 \pm 0.11$ & $6.67 \pm 0.46^{*}$ & $101 \pm 6$ & $205 \pm 9 *$ & $113 \pm 4$ & $129 \pm 5^{*}$ & $30 \pm 2$ & $31 \pm 4$ \\
\hline & 5 & $12.5 \pm 0.7$ & $2.74 \pm 0.15$ & $5.51 \pm 0.40^{*} \ddagger$ & $74 \pm 1 \neq$ & $160 \pm 4^{*} \ddagger$ & $106 \pm 3$ & $116 \pm 1^{*} \ddagger$ & $35 \pm 3$ & $34 \pm 2$ \\
\hline \multirow[t]{2}{*}{ Exercise } & 0 & $11.8 \pm 0.7$ & $2.91 \pm 0.10$ & $5.66 \pm 0.27^{*}$ & $120 \pm 9$ & $186 \pm 10^{*}$ & $105 \pm 3$ & $113 \pm 4^{*}$ & $25 \pm 2$ & $31 \pm 2 *$ \\
\hline & 5 & $12.0 \pm 0.9$ & $3.06 \pm 0.36$ & $4.91 \pm 0.32 * \ddagger$ & $90 \pm 7 \ddagger$ & $137 \pm 10^{*} \downarrow$ & $113 \pm 4$ & $118 \pm 6$ & $37 \pm 8$ & $38 \pm 6 \ddagger$ \\
\hline
\end{tabular}

Values are mean $\pm \mathrm{SE} ; n=6$ in each group.

* Exercise values that are statistically different from their corresponding resting values in the same group of animals at $P<0.05$, as determined by Student's $t$ test for paired comparisons.

$\$$ Values at week 5 that are statistically different from their corresponding values at week 0 in the same group of animals at $P<0.05$, as determined by Student's $t$ test for paired comparisons. 

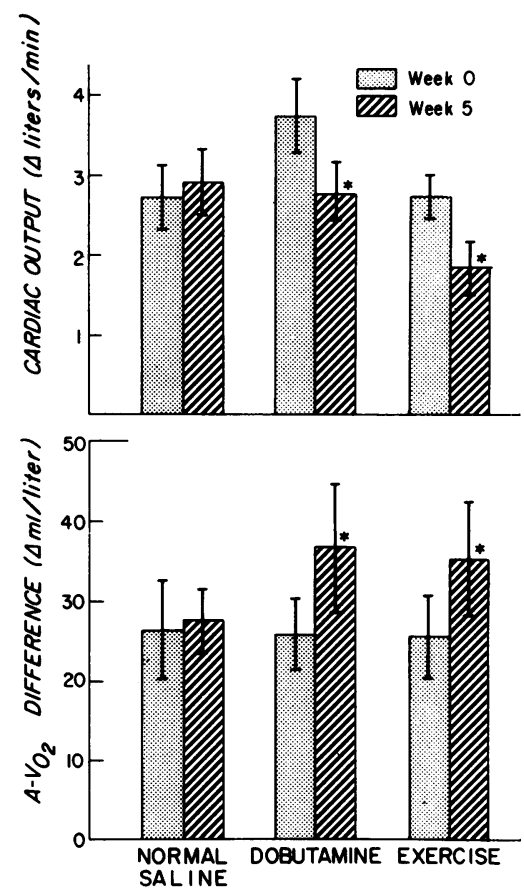

FIGURE 2 Increases in cardiac output and arteriovenous oxygen $\left(\mathrm{A}-\mathrm{VO}_{2}\right)$ difference during exercise in the three groups of animals at week 0 and week 5. $n=6$ in each group. Bars show SE. *, Values that are statistically different from corresponding values at week 0 in the same group of animals at $P<0.05$, as determined by Student's $t$ test for paired comparisons.

sure, and heart rate were similar among the three groups (Table I). Stroke volume did not change significantly during exercise in the groups subsequently infused with normal saline or dobutamine, but in the group subsequently conditioned with exercise it increased slightly.
Table I also shows that resting values of cardiac output and mean aortic blood pressure did not differ significantly between week 0 and week 5 in any of the groups, whereas, as shown in Fig. 1, the resting heart rate decreased at week 5 in the groups of dogs with dobutamine infusion and exercise training. The average values of resting stroke volume increased in the latter two groups at week 5, but these changes did not reach statistical significance.

Repeat treadmill exercise at week 5 increased total body oxygen consumption to $413 \pm 44,457 \pm 29$, and $390 \pm 25 \mathrm{ml} / \mathrm{min}$, in the normal saline, dobutamine, and exercise groups, respectively. The increases were indistinguishable from those that occurred during the initial treadmill exercise. Also in the normal saline group, the increases in cardiac output, mean aortic blood pressure, heart rate, and arteriovenous oxygen difference (from $41 \pm 4$ to $68 \pm 5 \mathrm{ml} /$ liter, $P<0.01$ ) during treadmill exercise at week 5 were the same as those that occurred at week 0 . In contrast, at week 5 the increases in cardiac output, mean aortic blood pressure, and heart rate during exercise were smaller than at week 0 in the dobutamine and exercise groups (Table I). The arteriovenous oxygen difference during exercise at week $5(87 \pm 7 \mathrm{ml} /$ liter $)$ was larger than at week $0(67 \pm 4 \mathrm{ml} /$ liter, $P<0.01)$ in the dobutamine group. Similarly in the exercise group, the smaller increase in cardiac output during treadmill exercise at week 5 was associated with a larger arteriovenous oxygen difference (Fig. 2).

Metabolic and hormonal responses to treadmill exercise. Treadmill exercise increased arterial blood $\mathrm{pH}$ from $7.41 \pm 0.01$ to $7.47 \pm 0.03(P<0.01)$ and decreased $\mathrm{PCO}_{2}$ from $35 \pm 1$ to $28 \pm 2 \mathrm{~mm} \mathrm{Hg}(P<0.01)$, but did not affect $\mathrm{PO}_{2}(90 \pm 3$ to $91 \pm 2 \mathrm{~mm} \mathrm{Hg})$ in the normal saline group. Similar $\mathrm{pH}$ and $\mathrm{PCO}_{2}$ changes

TABLE II

Biochemical Measurements

\begin{tabular}{|c|c|c|c|c|c|c|c|c|c|}
\hline \multirow[b]{3}{*}{ Group } & \multirow[b]{3}{*}{ wk } & \multicolumn{4}{|c|}{ Arterial blood } & \multicolumn{4}{|c|}{ Arterial plasma } \\
\hline & & \multicolumn{2}{|c|}{ [Lactate] } & \multicolumn{2}{|c|}{ [Lactate]:[Pyruvate] } & \multicolumn{2}{|c|}{ Renin activity } & \multicolumn{2}{|c|}{ [Norepinephrine] } \\
\hline & & Resting & Exercise & Resting & Exercise & Resting & Exercise & Resting & Exercise \\
\hline & \multicolumn{3}{|c|}{$m M$} & & & \multicolumn{2}{|c|}{$n g / m l / h$} & \multicolumn{2}{|c|}{$n g / m l$} \\
\hline Normal saline & $\begin{array}{l}0 \\
5\end{array}$ & $\begin{array}{l}1.43 \pm 0.26 \\
1.25 \pm 0.20\end{array}$ & $\begin{array}{l}2.78 \pm 0.59^{*} \\
3.11 \pm 0.74^{*}\end{array}$ & $\begin{array}{l}5.35 \pm 0.41 \\
5.11 \pm 0.59\end{array}$ & $\begin{array}{l}7.84 \pm 1.03^{*} \\
8.63 \pm 0.93^{*}\end{array}$ & $\begin{array}{l}2.6 \pm 0.5 \\
2.5 \pm 0.3\end{array}$ & $\begin{array}{l}4.6 \pm 1.1^{*} \\
6.0 \pm 1.2^{*}\end{array}$ & $\begin{array}{l}0.26 \pm 0.03 \\
0.24 \pm 0.04\end{array}$ & $\begin{array}{l}0.92 \pm 0.11^{*} \\
0.95 \pm 0.05^{*}\end{array}$ \\
\hline Dobutamine & $\begin{array}{l}0 \\
5\end{array}$ & $\begin{array}{l}1.23 \pm 0.25 \\
0.68 \pm 0.20\end{array}$ & $\begin{array}{l}4.09 \pm 0.54^{*} \\
2.72 \pm 0.49^{*}\end{array}$ & $\begin{array}{l}5.74 \pm 0.58 \\
4.23 \pm 0.68\end{array}$ & $\begin{array}{c}10.14 \pm 0.85 \\
8.17 \pm 0.49^{*} \downarrow\end{array}$ & $\begin{array}{l}2.3 \pm 0.8 \\
1.4 \pm 0.2\end{array}$ & $\begin{array}{l}4.6 \pm 0.9^{*} \\
2.7 \pm 0.7^{*} \ddagger\end{array}$ & $\begin{array}{l}0.29 \pm 0.03 \\
0.11 \pm 0.02\end{array}$ & $\begin{array}{l}0.91 \pm 0.12 * \\
0.38 \pm 0.08 * \uparrow\end{array}$ \\
\hline Exercise & $\begin{array}{l}0 \\
5\end{array}$ & $\begin{array}{l}1.24 \pm 0.29 \\
0.53 \pm 0.05 \ddagger\end{array}$ & $\begin{array}{l}2.31 \pm 0.65^{*} \\
0.90 \pm 0.08^{*}\end{array}$ & $\begin{array}{l}5.08 \pm 0.76 \\
4.32 \pm 0.64\end{array}$ & $\begin{array}{l}7.46 \pm 1.20^{*} \\
5.96 \pm 0.49^{*}\end{array}$ & $\begin{array}{l}2.4 \pm 0.5 \\
2.1 \pm 0.4\end{array}$ & $\begin{array}{l}7.3 \pm 2.3^{*} \\
3.9 \pm 1.0^{*} \ddagger\end{array}$ & $\begin{array}{l}0.33 \pm 0.04 \\
0.24 \pm 0.04 \ddagger\end{array}$ & $\begin{array}{l}0.85 \pm 0.12 * \\
0.56 \pm 0.12 * \ddagger\end{array}$ \\
\hline
\end{tabular}

Values are mean $\pm \mathrm{SE} ; n=6$ in each group.

* Same as in Table I.

‡ Same as in Table I. 
occurred in the other two groups during both the initial and final treadmill exercise. Table II shows that treadmill exercise increased arterial blood lactate, lactate: pyruvate ratio, plasma renin activity, and norepinephrine concentration. These metabolic and hormonal responses to initial exercise at week 0 were similar in all three groups. At week 5, the arterial blood lactate concentration, plasma renin activity, and norepinephrine concentration at rest were all significantly lower than before in the dobutamine group. The resting values of arterial blood lactate and plasma norepinephrine concentrations also decreased at week 5 in the exercise group. Furthermore, dobutamine infusion and exercise training reduced the increases in blood lactate, plasma renin activity, and norepinephrine concentration that occurred during treadmill exercise at week 5 . The increase in blood lactate:pyruvate ratio during exercise was also smaller at week 5 as compared to week 0 in the dobutamine group. In contrast, none of these measurements changed significantly in the normal saline group.

Methoxamine infusion. Methoxamine infusion increased aortic and left atrial pressures, and decreased heart rate in all animals. Left atrial pressure did not differ between the week 0 and week 5 studies before methoxamine infusion. It increased maximally to 25 $\mathrm{mm} \mathrm{Hg}$ during methoxamine infusion, which, as indicated by left atrial phasic pressure contours, did not cause mitral regurgitation. In addition, the decreased levels of heart rate during methoxamine infusion were comparable in the normal saline, dobutamine, and exercise groups. At week 5 , the values of heart rate at the end of methoxamine infusion were $63 \pm 6,57 \pm 4$, and $61 \pm 3$ beats $/ \mathrm{min}$ in the three experimental groups, respectively.

Left ventricular function curves were constructed in each dog by plotting systolic aortic blood pressure against either mean left atrial pressure or the logarithm of the mean left atrial pressure. Analysis of variance shows that the two methods yielded $F$ values of 161.2 \pm 22.6 and $112.8 \pm 19.8$, respectively $(n=36)$. Because the logarithmic transformation of mean left atrial pressure does not reduce the variance for the linear regression, only results of the former method are reported. The slope of the line relating systolic aortic blood pressure and mean left atrial pressure was computed for each dog and is termed the "left ventricular function index." This index did not differ significantly among the three experimental groups at week 0 . At week 5 , it increased significantly in the dobutamine and exercise groups (Fig. 3). In contrast, it did not change significantly in the normal saline group.

Left ventricular weights and blood flows. At autopsy, left ventricular weight did not differ among the three experimental groups (Table III). Left ventricular blood flows in the dobutamine and exercise groups,

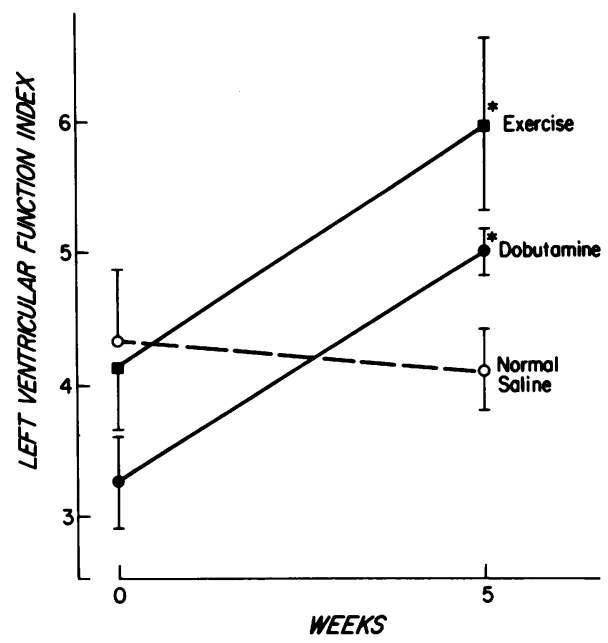

FIGURE 3 Changes in left ventricular function index after 5-wk programs of treadmill exercise, dobutamine infusion, and normal saline infusion. $n=6$ in each group. Bars show SE. *, Values that are statistically different from their corresponding values at week 0 in the same group of animals at $P<0.01$.

however, were significantly lower than that in the normal saline group.

\section{DISCUSSION}

This study shows that chronic infusion of dobutamine produced a conditioning effect similar to that which occurs after exercise training. Our animals were confined to individual cages for $3 \mathrm{wk}$ before entering an exercise or infusion program. The purpose of the cage confinement (21) was to decondition some of the animals that might have been previously physically trained. Our results show that after the 5-wk program of dobutamine infusion and physical exercise, heart rate, blood lactate, plasma norepinephrine, and plasma renin activity were reduced both at rest and during exercise. In addition, the cardiac output during the same exercise work load was smaller, whereas arteriovenous

TABLE III

Left Ventricular Weights and Blood Flows

\begin{tabular}{lccc}
\hline \multirow{2}{*}{ Group } & \multicolumn{2}{c}{ Left ventricular } & \\
\cline { 2 - 3 } & wt & Blood flow & $\begin{array}{c}\text { Left ventricular wt: } \\
\text { total body wt }\end{array}$ \\
\hline Normal saline & $54 \pm 5$ & $207 \pm 27$ & $\%$ \\
Dobutamine & $60 \pm 3$ & $126 \pm 8^{*}$ & $5.2 \pm 0.4$ \\
Exercise & $58 \pm 5$ & $135 \pm 11^{*}$ & $4.8 \pm 0.2$ \\
\hline
\end{tabular}

Values are mean $\pm \mathrm{SE} ; n=6$ in each group.

* Values that are statistically different from that in the normal saline group at $P<0.05$, as determined by Dunnett's test (20). 
oxygen difference was larger in the two groups at week 5 than week 0 . Myocardial contractility, as determined by left ventricular function index, also increased. None of these changes occurred in the animals that received normal saline infusion. Furthermore, left ventricular blood flow was lower in the dobutamine and exercise groups than in the normal saline group. These differences in myocardial blood flow among the groups might be explained in part by their variations in heart rate.

A slower resting heart rate and cardiac hypertrophy are two of the characteristic findings after physical training $(1,2)$. The increase in cardiac size occurred in rats after daily exercise $1 \mathrm{~h}$ a day for 10 consecutive wk, but did not occur in rats after intermittent exercise twice a week for $10 \mathrm{wk}(22)$. Left ventricular wall thickness was reported to increase in dogs after $12 \mathrm{wk}$ of treadmill exercise $1 \mathrm{~h}$ a day, $5 \mathrm{~d}$ a week, but left ventricular end-diastolic volume did not increase (23). In our study with a 5-wk treadmill exercise program, left ventricular weight did not increase. Left ventricular weights also did not increase in dogs after an 8- to 10-wk treadmill running program (24). Likewise, daily dobutamine infusion for $5 \mathrm{wk}$ did not increase left ventricular weight (Table III). Heart to body weight ratio, nevertheless, has been shown to increase after an 18-wk infusion of dobutamine (8).

In this study, the reduced concentration of plasma norepinephrine suggests that dobutamine infusion and exercise training diminished the endogenous release of norepinephrine. Decreased sympathetic activity may be responsible for the reduced plasma renin activity during treadmill exercise in these two groups of animals. It also may account for the reduced heart rate both at rest and during treadmill exercise. This is in accord with decrease in cardiac catecholamine content (25) and a smaller increase in coronary sinus catecholamine concentration during exercise in physically trained subjects (26). Our results, however, do not exclude the possibility that the relative bradycardia may also be caused by an enhanced vagal tone or a decreased sensitivity of adrenergic receptors. Both of these mechanisms have been postulated to explain the bradycardia produced by physical training $(4,27,28)$.

The increases in heart rate, mean aortic blood pressure, and cardiac output observed during the standardized submaximal exercise were smaller after $5 \mathrm{wk}$ of dobutamine infusion and treadmill exercise (Table I). Although these changes might be explained in part by the reduced sympathetic activity in these two groups of animals (Table II), they could also be causally related to the biochemical adaptations of skeletal muscle $(3,29,30)$. It has been shown in man (31) that the characteristic reduction in heart rate response to exercise is seen only if the exercise involves the trained muscle group. The reduction in heart rate obtained by training of one muscle group cannot be transferred to work performed with untrained muscle groups.

In our experiments with methoxamine infusion, left atrial pressure was related to the systolic aortic pressure. This ventricular pressure-function curve (32) is a valid index of left ventricular contractility if there is no change in left ventricular compliance. Physical training does not alter left ventricular compliance (33). Thus, the increase in the slope of the pressure-function curve (left ventricular function index in Fig. 3) could be used to indicate that myocardial contractility increased in the dobutamine and exercise groups. Other investigators have shown that the mechanical performance of the heart is improved in physically conditioned animals $(4,33,34)$, but the biochemical adaptation in cardiac muscle responsible for the increase in myocardial contractility has not been fully elucidated $(1,24,35)$.

This study further suggests that the conditioning effects produced by physical training may be caused by exercise-induced sympathetic stimulation. This is supported by the findings that prolonged infusion of norepinephrine not only produced myocardial hypertrophy (36), but also enhanced myocardial contractility in dogs (37), and that immunologic sympathectomy abolished the increase in heart to body weight ratio produced by chronic exercise in rats (38). In addition, like physical training, repeated injections of catecholamines cause an increased sensitivity to the metabolic effects of norepinephrine (39), which probably is responsible for the enhanced lipid oxidation in trained subjects during exercise (40). Finally, dobutamine is less likely than are the naturally occurring catecholamines to cause dangerous changes in cardiac rhythm or arterial blood pressure, or to induce myocardial necrosis $(9,10$, data on file at the Lilly Research Laboratories). Further experiments are needed to study the potential use of dobutamine infusion as an alternative approach to exercise for patients, who for various reasons must remain physically inactive, to achieve conditioning effects.

\section{ACKNOWLEDGMENTS}

The authors thank Charles Scheller, Adele Rymut, Stephanie Arnold, Samuel Rivers, Song Que Lee, and Norma Moolten for their technical assistance and Deborah Walker for typing the manuscript. Indocyanine green (Cardio-Green) was generously supplied by Hynson, Westcott, \& Dunning, Inc., Baltimore, Md.

This work was supported in part by U. S. Public Health Service grants HL-17403, HL-18318, and HL-14646.

\section{REFERENCES}

1. Scheuer, J., and C. M. Tipton. 1977. Cardiovascular adaptations to physical training. Annu. Rev. Physiol. 39: 221-251. 
2. Clausen, J. P. 1977. Effect of physical training on cardiovascular adjustments to exercise in man. Physiol. Rev. 57: 779-815.

3. Holloszy, J. O., and F. W. Booth. 1976. Biochemical adaptations to endurance exercise in muscle. Annu. Rev. Physiol. 38: 273-291.

4. Penpargkul, S., and J. Scheuer. 1970. The effect of physical training upon the mechanical and metabolic performance of the rat heart. J. Clin. Invest. 49: 1859-1868.

5. Poortmans, J. R., editor. 1969. Biochemistry of Exercise. S. Karger AG, Basel, Switzerland.

6. Von Euler, U.S. 1974. Sympatho-adrenal activity in physical exercise. Med. Sci. Sports. 6: 165-173.

7. Himms-Hagen, J. 1967. Sympathetic regulation of metabolism. Pharmacol. Rev. 19: 367-461.

8. Tuttle, R. R., N. Bowling, B. MacDonald, and G. D. Pollock. 1977. Dobutamine simulates the effects of physical training on coronary and ventricular reserve after myocardial infarction. Am. J. Cardiol. 39: 298. (Abstr.)

9. Sonnenblick, E. H., W. H. Frishman, and T. H. LeJemtel. 1979. Dobutamine: a new synthetic cardioactive sympathetic amine. N. Engl. J. Med. 300: 17-22.

10. Tuttle, R. R., and J. Millis. 1975. Dobutamine. Development of a new catecholamine to selectively increase cardiac contractility. Circ. Res. 36: 185-196.

11. Ramsey, L. H. 1959. Analysis of gas in biological fluids by gas chromatography. Science (Wash. D. C.). 129: 900-901.

12. Friedland, E. M., and L. S. Dietrich. 1961. A rapid enzymic determination of $\mathrm{L}(+)$-lactic acid. Anal. Biochem. 2: $390-392$.

13. Huckabee, W. E. 1956. Control of concentration gradients of pyruvate and lactate across cell membranes in blood. J. Appl. Physiol. 9: 163-170.

14. Sealey, J. E., J. Gerten-Banes, and J. H. Laragh. 1972. The renin-system: variations in man measured by radioimmunoassay or bioassay. Kidney Int. 1: 240-253.

15. Henry, D. P., B. J. Starman, D. G. Johnson, and R. H. Williams. 1975. A sensitive radio-enzymatic assay for norepinephrine in tissues and plasma. Life Sci. 16: 375-384.

16. Innes, I. R., and M. Nickerson. 1975. Norepinephrine, epinephrine, and the sympathomimetic amines. In The Pharmacological Basís of Therapeutics. L. S. Goodman and A. Gilman, editors. Macmillan, Inc. New York. 5th edition. 477-513.

17. Liang, C-s. 1977. Metabolic control of circulation. Effects of iodoacetate and fluoroacetate.J. Clin. Invest. 60: 61-69.

18. Rudolph, A. M., and M. A. Heymann. 1967. The circulation of the fetus in utero: methods for studying distribution of blood flow, cardiac output and organ blood flow. Circ. Res. 21: 163-184.

19. Winer, B. J. 1971. Statistical Principles in Experimental Design. McGraw-Hill, Inc., New York. 2nd edition. 261-300.

20. Dunnett, C. W. 1964. New tables for multiple comparisons with a control. Biometrics. 20: 482-491.

21. Tipton, C. M., R. A. Carey, W. C. Eastin, and H. H. Erickson. 1974. A submaximal test for dogs: evaluation of effects of training, detraining, and cage confinement. J. Appl. Physiol. 37: 271-275.

22. Leon, A. S., and C. M. Bloor. 1968. Effects of exercise and its cessation on the heart and its blood supply. $J$. Appl. Physiol. 24: 485-490.

23. Wyatt, H. L., and J. H. Mitchell. 1974. Influences of physical training on the heart of dogs. Circ. Res. 35: 883-889.
24. Dowell, R. T., H. L. Stone, L. A. Sordahl, and G. K. Asimakis. 1977. Contractile function and myofibrillar ATPase activity in the exercise-trained dog heart. $J$. Appl. Physiol. Respir. Environ. Exercise Physiol. 43: 977-982.

25. De Schryver, C., J. Mertens-Strythagen, I. Becsei, and J. Lammerant. 1969. Effect of training on heart and skeletal muscle catecholamine concentration in rats. Am. J. Physiol. 217: 1589-1592.

26. Cousineau, D., R. J. Ferguson, J. de Champlain, P. Gauthier, P. Côte, and M. Bourassa. 1977. Catecholamines in coronary sinus during exercise in man before and after training. J. Appl. Physiol. Respir. Environ. Exercise Physiol. 43: 801-806.

27. Herrlich, H. C., W. Raab, and W. Gigee. 1966. Influence of muscular training and of catecholamines on cardiac acetylcholine and cholinesterase. Arch. Int. Pharmacodyn. Ther. 129: 201-215.

28. Brundin, T., and C. Cernigliaro. 1975. The effect of physical training on the sympathoadrenal response to exercise. Scand. J. Clin. Lab. Invest. 35: 525-530.

29. Keul, J., E. Doll, and D. Keppler. 1972. Energy Metabolism of Human Muscle. University Park Press, Baltimore, Md. 244-255.

30. Holloszy, J. O., F. W. Booth, W. W. Winder, and R. H. Fitts. 1975. Biochemical adaptation of skeletal muscle to prolonged physical exercise. In Metabolic Adaptation to Prolonged Physical Exercise. H. Howald and J. R. Poortmans, editors. Birkhäuser Verlag., Basel, Switzerland. 438-447.

31. Clausen, J. P., J. Trap-Jensen, and N. A. Lassen. 1970. The effects of training on the heart rate during arm and leg exercise. Scand. J. Clin. Lab. Invest. 26: 295-301.

32. Goodyer, A. V. N., M. J. Goodkind, and A. B. Landry. 1962. Ventricular response to a pressure load. Left ventricular function curves in intact animals. Circ. Res. 10: 885-896.

33. Bersohn, M. M., and J. Scheuer. 1977. Effects of physical training on end-diastolic volume and myocardial performance of isolated rat hearts. Circ. Res. 40: 510-516.

34. Stone, H. L. 1977. Cardiac function and exercise training in conscious dogs. J. Appl. Physiol. Respir. Environ. Exercise Physiol. 42: 824-832.

35. Tibbits, G., B. J. Koziol, N. K. Roberts, K. M. Baldwin, and R. J. Barnard. 1978. Adaptation of the rat myocardium to endurance training. J. Appl. Physiol. Respir. Environ. Exercise Physiol. 44: 85-89.

36. Laks, M. M., F. Morady, and H. J. C. Swan. 1973. Myocardial hypertrophy produced by chronic infusion of subhypertensive doses of norepinephrine in the dog. Chest. 64: 75-78.

37. Laks, M. M., D. Garner, and V. Wong. Increase in ejection fraction produced by long-term subhypertensive infusion of norepinephrine in conscious dogs. Am. Heart J. In press.

38. Tipton, C. M. 1965. Training and bradycardia in rats. Am. J. Physiol. 209: 1089-1094.

39. LeBlanc, J., J. Vallières, and C. Vachon. 1972. Betareceptor sensitization by repeated injections of isoproterenol and by cold adaptation. Am. J. Physiol. 222: 1043-1046.

40. LeBlanc, J., M. Boulay, S. Dulac, M. Jobin, A. Labrie, and S. Rousseau-Migneron. 1977. Metabolic and cardiovascular responses to norepinephrine in trained and nontrained human subjects. J. Appl. Physiol. Respir. Environ. Exercise Physiol. 42: 166-173. 